\title{
When a University Mathematics Department Adopted Core Mathematics Courses of an Unintentionally Constructionist Nature: Really?
}

\author{
Chantal Buteau $^{1}$ (D) Eric Muller $^{1} \cdot$ Neil Marshall $^{1}$
}

Published online: 23 November 2015

(C) Springer International Publishing 2015

\begin{abstract}
In a sequence of core mathematics courses instituted in 2001 at Brock University, students learn to design, program and use interactive computer environments, in order to investigate a self-stated mathematical conjecture, a concept, a theorem or a real-world situation. In this article, we provide documentation for the complete implementation process (design and adoption, actual implementation and student outcomes) of these technology-rich courses, underlining that their development occurred independent of ideas from the constructionism and microworld literature. However, we argue for their implicitly constructionist nature and explore the issue of a form of constructionist implementation acceptable to stakeholders in university mathematics education. Results of this exploratory case study propose three dominant elements for an adoptable description: i) students learning (to do) mathematics by programming and conducting their own mathematical explorations; ii) an explicit aim of empowering students articulated in pragmatic ways; iii) an implicit acknowledgement of constructionist student learning (e.g., through the explicit role of the instructor in fostering and valuing student creativity in mathematical work).
\end{abstract}

Keywords University mathematics · Constructionism - Implementation process · Adoption $\cdot$ Microworld $\cdot$ Exploratory objects

Very early on in the discussions of the use of digital technology in mathematics education, Papert (1980a) envisioned a reform of mathematics education where students would engage in mathematics learning in a very personal way. Papert (1991) later termed his approach Constructionism, a paradigm "unique in its attention to the ways in which meanings are generated during individual and collective bricolage with digital

Chantal Buteau

cbuteau@brocku.ca

1 Brock University, St Catharines, ON, Canada 
artefacts, influenced by negotiated changes students make to these artefacts and giving emphasis to ownership and production" (Kynigos 2015, p. 361). Papert's vision was exemplified by students engaging in mathematical work on Turtle geometry, the first example of a microworld, namely a self-contained world where students can "learn to transfer habits of exploration from their personal lives to the formal domain of scientific construction" (Papert 1980a, p. 177). Since then, there has been much research concerned with the impact on mathematics learning of using mathematics microworlds (e.g., Healy and Hoyles 1999; Hoyles and Noss 1987; Kynigos 2007; Sutherland 1987; Wilensky 1995).

The concept of microworld has evolved over time. Healy and Kynigos (2010) comment that, whereas mathematics microworlds were initially programmable environments accessible to the student, as technology grew more sophisticated, microworlds moved away from computer programming and toward more multimedia environments, as well as those that feature the dynamic manipulation of representations. Yet they also observe, "Programmability [...] has re-appeared recently with the advent of technologies allowing for programmable simulation-multimedia style tools" (p. 64). Indeed, some studies have shown how programming supports student understanding of mathematical concepts (e.g., Leron and Dubinsky 1995; Pesonen and Malvela 2000; Wilensky 1995) and contributes to the development of critical skills (e.g., Abrahamson et al. 2006; Marshall and Buteau 2014).

Most of the research on constructionism in university mathematics education has taken place in a research setting; for example, Wilensky (1995) describes the learning experience of a university student who used and modified a microworld to understand Bertrand's paradox. Only a few research projects have involved full-term, constructionism-based mathematics courses: for example, Mascaró et al. (2014) discuss biology masters students learning statistics by use of programming in R, while Kynigos (2007) examines how mathematics teacher graduate students engage in designing what he calls 'half-baked' microworlds. In fact, not only in university mathematics education, but overall, there have been relatively few sustained classroom implementations of microworlds (Healy and Kynigos 2010). They believe one reason could be that, "The ideas behind the microworld culture have not yet been presented in a form readily acceptable not only to school systems, but also to other stakeholders in education" (p. 68). However, this may change, as there has been a recent revival of programming in national school curricula in several countries - e.g., in France, Sweden, England and Estonia (Misfeldt and Ejsing-Duun 2015).

By contrast, at the university level, Buteau et al. (2014a) found in their national survey study that programming was the second most used mathematics technology by mathematicians in Canada in their research work after computer algebra systems (CAS). However, surprisingly, among all the eight mathematics technologies surveyed, only programming was not integrated to the same extent in teaching as it was in research. Our exploratory case study reported on here modestly addresses this issue of presenting a 'form readily acceptable to stakeholders' in the context of university mathematics education.

Our research involves a sustained implementation of a sequence of innovative courses over a dozen years in a university department of mathematics. In 2000, the Department of Mathematics and Statistics at Brock University revised its core undergraduate mathematics program, developed a philosophy for teaching and learning, and 
changed to a new program, called Mathematics Integrating Computers and Applications (MICA), which included the addition of three non-traditional and innovative core courses called MICA I-II-III (Ralph 2001). ${ }^{1}$ An overview of the MICA program can be found in Muller et al. (2009), who emphasize that it "values allocating time in class for the students to develop and explore conjectures, to put forward arguments, to discuss and develop their logic, and to trace their own problem solving processes" (p. 64). Furthermore, the MICA I-II-III courses "provide opportunities for students to use their creativity and to also develop intellectual independence [while] they develop and implement their own [exploratory objects]" (p. 64). More precisely, students in MICA courses learn to design, program and use interactive and dynamic computer-based tools (that we called exploratory objects) for the systematic investigation of a mathematical concept, theorem, self-stated conjecture or real-world situation; for examples, see the MICA url (n.d.).

The MICA courses did not evolve out of the constructionist movement. They were the brainchild of mathematician Bill Ralph and were subsequently endorsed by the department. In other words, these courses were initially designed (and adopted) within a mathematics department, without a mathematics education research context or purpose. Nevertheless, as a result of a recent literature review (Marshall and Buteau 2014), we have characterized exploratory objects as a 'microworlds type' (Marshall et al. 2014), which led us to believe that the MICA courses might constitute a constructionist approach. The investigation of the constructionist character of the MICA courses forms the first part of our study. In it, we explore elements and aspects used by the department (i.e., the stakeholders), in relation to constructionism, to describe the intended MICA courses. As such, the study aims to describe the elements of a 'form' that resonated with stakeholders in a university mathematics education context.

The innovation under study is beyond an individual instructor implementation: to date, five faculty (including Ralph) out of the current fourteen in the mathematics department and three (MICA graduate) part-time instructors have taught the MICA courses. Furthermore, the department has until now viewed these courses as part of the core of undergraduate mathematics education, alongside topics such as Calculus, Algebra and Statistics. Systemic innovation as part of core university mathematics courses is relatively rare, as highlighted by Hillel (2002):

Steen has written that 'strong departments find that they replace or change significantly half of their courses approximately once a decade' and 'as new mathematics is continually created, so mathematics courses must be continually renewed' (Steen 1992). These on-going updates to the curriculum can be regarded, in a sense, as 'deterministic' aspects of curriculum change, ones that do not put into question the purpose, goals, and means of undergraduate education. (p. 61)

\footnotetext{
${ }^{1}$ Changes to the program have occurred recently and should be live starting in Fall 2015, including the program name change to 'B.Sc. in Mathematics and Statistics'. MICA courses are now core requirements for four of the five concentrations, one of which is itself named MICA.
} 
This study thus also contributes an example of sustained constructionist implementation over 12 years in core courses within a university mathematics program.

In this article, ${ }^{2}$ we report on our exploratory case study focused on the question: How could constructionist mathematics courses at the university level be described in order for stakeholders to endorse and support its implementation? In the second section, we describe the theoretical framework of the study and in the third the methodology is presented. A documentation of the design and implementation of the sequence of MICA courses as part of a core undergraduate mathematics program forms the fourth section. In the subsequent section, we argue for the implicit constructionist character of the MICA course implementation, while in the sixth we examine the 'form' of the intended course implementation that was adopted by the stakeholders.

\section{Theoretical Framework}

For the purpose of our exploratory study, we view the complete process of implementation of an innovation through three different stages, starting with its design (stage 1), followed by its actual use (stage 2), and ending with student outcomes as a result of the innovation realization (stage 3). This simple model is in line with Fullan and Pomfret's (1977) discussion concerning implementation of educational innovations.

We describe stage 1 as encompassing "both intended or planned use and [... the] decision to use, the latter being defined as adoption" (Fullan \& Pomfret 1977, p. 336). This stage usually results in a form of description of intentions and planned use - e.g., of the intended objectives, mathematical content, tasks and learning outcomes - that ultimately get adopted by the policy makers. The innovation design process may involve, for example, a collaboration between teachers and education researchers who may or may not be part of those making the decision to adopt the innovation.

Stage 2, the implementation of the innovation proper, "refers to the actual use of an innovation or what an innovation consists of in practice" (p. 336). As Fullan and Pomfret stress, implementation is "not simply an extension of planning and adoption processes. It is a phenomenon in its own right" (p. 336). These authors add that:

the definition does not assume that an innovation is defined in advance by developers $[\ldots$ and $]$ that regardless of who develops an innovation, when it is developed, or how it is developed, some implementation will have occurred at the point when certain new characteristics are actually in use in a social system. (p. 336; emphasis in original)

This would support the view that, for example, a constructionist implementation could 'un-intentionally' take place if all characteristics of such an implementation were realized. We describe stage 2 as involving the implemented innovation by the teacher and students in the form of a sequence of realized (mathematical) tasks within or outside (e.g., assignment) the classroom, including an account of the teacher/student roles during their activity. This stage involves both the teacher and students wherein the

\footnotetext{
${ }^{2}$ This article elaborates on work presented at the Constructionism and Creativity conference: (Buteau et al. 2014c).
} 
teacher 'provides' an instructional intervention that is 'received' by the students (Zvoch 2012). In short, the teacher facilitates a learning environment in which s/he guides and/ or invites students to participate in certain ways. Stage 3 of the complete process of implementation of an innovation concerns student outcomes, (i.e., student achievement). It may, for example, take the form of a description of individual and/or collective knowledge and competencies learned through the innovation implementation. This stage is thus solely related to students.

In university education, the 'teacher' and 'students' involved in stages 2 and 3 of the implementation process are generally well understood. These individuals occupy somewhat similar roles to those in school education. However, there is a notable difference between university and school education contexts for the 'stakeholders' involved in the innovation designed in stage 1 . In many school systems, a reform in curriculum is initiated through a political system and a 'committee' of stakeholders is struck that may include teachers, school board members, educational experts from the discipline and from education as well as individuals from other interested parties. In other words, only a small percentage of the 'stakeholders' from stage 1 are involved as 'teachers' in stage 2. By contrast, in a university department or teaching unit, the 'stakeholders' involved in the design stage represent a majority or all of the members of the department or teaching unit (Buteau and Muller 2014). This is especially true when the innovation is focused on core or required components of the program.

Within this model of the implementation process of an innovation, we now embed principles of constructionism, defined by Papert (1991) in the following way:

Constructionism - the $\mathrm{N}$ word as opposed to the V word - shares constructivism's connotation of learning as 'building knowledge structures' irrespective of the circumstances of the learning. It then adds the idea that this happens especially felicitously in a context where the learner is consciously engaged in constructing a public entity, whether it's a sand castle on the beach or a theory of the universe. (p. 1)

Thus, the basic principles of the constructionist paradigm involve learning situations or environments that are student-centred, where students build or construct shareable objects that are somehow 'tangible' (Papert 1990). In other words, it involves learning through making (Papert 1991). Through activity, learners are 'consciously engaged' in the construction (i.e., the learner must be reflective about his/her construction work). The other key characteristic defining constructionism is an engagement in meaningful projects: "people construct new knowledge with particular effectiveness when they are engaged in constructing personally meaningful products [..., i.e., ] something meaningful to themselves and to others around them" (Kafai and Resnick 1996, p. 214).

Although usually not explicitly mentioned when defining constructionism, two other ideas are often connected to it. First, the idea of students engaging in "powerful ideas" (Papert 1980a). Take, for example, the powerful idea mentioned by Papert in the 1972 Second International Congress on Mathematics Education: "Let the student learn mathematics as applied mathematics [...] in the sense that mathematical knowledge is an instrument of power, making it possible to do things of independent worth that one could not otherwise do" (as reported in Hoyles 2014). The idea of students engaging with powerful ideas is related to giving students a sense of empowerment 
(Papert 1996). For example, Papert (1980a) stresses this characteristic in the context of Turtle geometry: "Each new idea in Turtle geometry opened new possibilities for action and could therefore be experienced as a source of personal power" (p. 129). Second, the idea of creativity has been connected to constructionism from its early days. Girvan (2014) observes: “"A creative act is an instance of learning' (Guilford 1950) and throughout constructivist learning experiences there is evidence of learners engaging in the construction of creative artefacts to explore, test and extend their understanding" (p. 367).

Constructionist situations usually involve open projects that are often computerbased, e.g., with the Turtle geometry microworld. For Papert (1980b), microworlds involve objects "to think with" and "allow a human learner to exercise particular powerful ideas or intellectual skills" (p. 204) through exploration and discovery in a knowledge domain. As mentioned earlier, the concept of microworld has evolved over time: A recent definition of microworld is provided by Mavrikis et al. (2008):

Mathematical microworlds belong to a particular genre of exploratory learning environments (ELEs) that allow students to explore not only the structure of accessible objects in the environment, but also construct their own objects and explore the mathematical relationships between and within the objects, as well as the representations that make them accessible. (p. 41)

Furthermore, Hoyles and Noss (2014) indicate that constructionism as a theoretical framework should be categorized as a 'framework for actions', that is, "guiding principles that would help you make decisions of the kind 'what should I do next?', 'how does one piece of information relate to another piece of information?'" (8:04). In line with their categorization of constructionism as a framework for action, its defining characteristics can mainly be identified in stage 2 of the implementation model. Indeed, the construction of shareable, meaningful objects and the student-centred characteristic of the task is localised in the learning environment facilitated by the teacher (hence stage 2). It is in this environment that the learner might reflectively engage in the construction of products, and thereby learn, which crosses over from stage 2 to stage 3 , the student outcome stage. A learner's sense of empowerment is also part of this latter stage. In short, in addition to the characteristics mentioned above about the implementation, the specifics of the classroom tasks should be such that they prompt (or have the intention to prompt - design stage 1) student learning and empowerment.

\section{Methodology}

Our exploratory case study addresses: How could a constructionist mathematics course be described in order for stakeholders to endorse and support the implementation? The case study method is well justified due to our focus on "how" and which contexts are relevant to the phenomenon under study (Yin 2003). There are two main parts to this study: 1) the characterization of the MICA course implementation as constructionist; 2) the description of this constructionist innovation that enabled stakeholders to endorse it. We examine this implementation using the three stages described in the previous section. This analysis results in a documentation of the course implementation in the 
next section that is then analyzed by identifying: i) its constructionist characteristics in the section after that, and ii) dominant elements used in the final formal course description in relation to constructionism in the penultimate one.

For the design and adoption stage, two types of data were collected. First, a two-hour informal interview was conducted in 2013 with Bill Ralph, the principal faculty developer of the MICA courses. The aim was both to explore the ideas, intentions and insights that led him to propose the MICA I-II-III courses and also to provide some understanding of the course design intentions. Second, the official documents recording the department's adoption of the MICA courses were studied. These included: i) the unpublished document proposing a new undergraduate program (i.e., the MICA program) written by the departmental Task Force Committee (TFC) in 1999-2000; ii) the Brock University Calendars since 2002 listing course descriptions; iii) the 201314 course outlines by the MICA I-II teaching faculty. These documents are justifiable as relevant sources due to the double role of faculty as decision makers for the departmental adoption of the courses and as teachers of the courses themselves. Relevant excerpts in these documents were selected and chronologically summarized according to each MICA course.

The innovation implementation stage is addressed through a description of the mathematics tasks within each of the courses. No data was additionally collected for this stage as we three authors collectively have a profound knowledge of the MICA courses and possess all course material. Indeed, Muller was Chair of the department when the MICA program was developed; Buteau has taught MICA I since 2005, and ever since then has been carrying out, with Muller, reflective work about MICA courses; Marshall is a graduate from the MICA program who has worked as a teaching assistant for the MICA I and MICA III courses, and who also joined Buteau and Muller in 2010 in their reflective work on these courses. Based on our understanding of MICA courses and building on these different perspectives in implementation (including lecture notes, assignment guidelines, course outlines, attending computer lab sessions, etc.), we describe the course tasks. Despite the fact that self-reports can be inaccurate and misleading (Fullan and Pomfret 1977), we nonetheless claim that our diverse roles on the MICA courses have contributed to the accuracy of the description as a kind of triangulation method.

The student outcome stage is looked at through the students' views of their MICA course experience. For this part, we use data from a previous study (Buteau et al. $2014 c, d)$. A voluntary and anonymous on-line survey was conducted during laboratory sessions of the MICA I-II courses in March 2013. One of the questions asked participants to describe the MICA courses to a fictitious student from another institution, and their responses provide insights into students' own (learning) experiences and views on the MICA courses. Students' responses were examined with an emerging theme approach. In total, 60 MICA students voluntarily participated in the study distributed as follows: 27 MICA I students, 29 MICA II students, and 4 MICA teaching assistants (all of whom were themselves former MICA students); 26 female and 34 male students; 23 mathematics majors, 25 future mathematics teachers, and 12 students enrolled in other programs. This student sample represented $57 \%$ of the MICA student population and was broadly representative of the MICA I and MICA II demographic, but with a slight numerical bias towards responses by male students and future mathematics teachers. 


\section{A History of Microworld-Based MICA Course Implementation: from their Creation to the Student Experience}

In this section, we present a documentation of the MICA course implementation: the ground ideas that led to the courses in the first sub-section; the formal description of the courses adopted by the department in the second; classroom implementation in the third; the student learning experience in the last.

\section{The Design: Leading to the Creation of the MICA I-II-III Courses - Why? How? What?}

The creation of the MICA I-II-III courses evolved mainly from Bill Ralph's outline and recommendations, which were used by the Brock departmental TFC to develop a new teaching and learning philosophy for the Department. The new core MICA courses were designed, recommended, and first taught by him. As a mathematician, Ralph has broad mathematical interests as demonstrated by his research in financial mathematics, algebraic topology, mathematical arts, modelling and simulation where he often assists researchers in other disciplines. He is also a person with great artistic talents (pianist, visual artist). In his teaching, Ralph has an honest interest in his students' success in both life and mathematics. From a recent pragmatic publication (Ralph 2014), one can gain access to his most current views of technology use in mathematics education, where he proposes:

In a future that accommodates both the traditional and technological flavours of mathematics, students might be encouraged to learn two complementary types of knowledge: autonomous knowledge consisting of skills and memorized facts that can be demonstrated without the assistance of technology, and linked knowledge that is contingent upon access to expert systems. (p. 22; emphasis in original)

Ralph lists some of the mathematics education tasks that will need to be included for students to develop their expertise in linked knowledge. This list includes, among others, "Using expert systems to explore concepts and perform calculations" and "Writing and using computer programs to build models, create simulations and investigate mathematical problems" (p. 22) which, as we will see in the following, have served to shaped the MICA courses.

When asked in a two-hour interview about why he came to create the MICA courses, Ralph identified two important influences: external reality and his personal experiences. First and foremost, 'external reality' meant the decreasing number of mathematics majors at Brock University, a concern for many university mathematics departments at the turn of this century. As well, Ralph was aware that most of Brock's mathematics majors were not pursuing graduate studies, but entering the work force. At the time, he felt that the atmosphere and the degree of collegiality in the mathematics department were such that major changes would be seriously considered. He foresaw the opportunities offered by this changing environment and was given a half-year course release by the Chair to develop and recommend a reform of program(s) for mathematics majors, a task he took very seriously. These recommendations led to the creation of the sequence of core MICA I-III courses. 
In the area of his personal experiences, Ralph mentioned that he had previously taken a 3-year leave of absence from 1995 to 1998 to design and implement, with a professional team, his Journey Through Calculus software (Ralph 1999). This experience caused him to rethink ideas concerning mathematics education at the undergraduate level in a technological era. He had taught undergraduate mathematics with digital technologies since the late 1980s. In addition, for many years he had volunteered and worked with individual mathematically talented school students from the Niagara Region. These students had completed the Ontario school mathematics curriculum well ahead of the usual schedule, and teachers turned to the mathematics department for assistance in continuing to engage them in mathematics. Ralph looked for creative projects for the students to investigate and came up with new ways to present mathematical ideas. He found that these students, many of whom had a programming background, became completely immersed in their learning when they programmed an exploration of a mathematical concept or application and then communicated their understanding visually through an interface. He was pleasantly surprised by their engagement and enthusiasm, and also by the amount of time they were willing to devote to their tasks.

Ralph said that one of his priorities was always to structure his teaching environments so that students would have fun and be engaged when they learned to do mathematics. He found that students could have fun and be engaged in different situations, for example, when they felt they were being creative, working in selfselected projects, achieving in tasks independently, or discovering an unexpected result. When Ralph tutored a mathematically talented school student, he offered some flexibility for the individual to choose an area of mathematical interest, and he supported the student's aptitude to program as a means to creatively explore mathematical concepts and applications. These experiences, together with his research experience, contributed to an evolution of his view that programming be an integral part of numeracy.

In developing the MICA courses, Ralph commented that he aimed at re-creating the individual experience of his gifted students in a mathematics class. He wanted students to be creative and personally involved so that each one could claim: "I did something related to me". He envisioned a classroom rich with discussion and interaction with classmates, faculty and technology. Ralph envisaged a MICA terminal degree that would meet the needs of a great majority of our mathematics students who do not continue into graduate studies - a terminal degree that would provide a rich experience for exploring and using mathematics in wide-ranging work environments. The MICA program would include developing a capacity for programming and gaining experience in experimentation, simulation and modelling. This, together with elements of the elaborated teaching philosophy, is actually how he described the MICA courses. As will be seen in the next sub-section, this was reflected in the new program proposal, including the innovative core MICA I-II-III courses, submitted to the department in 2000 by the TFC, of which Ralph was Chair.

\section{The Adoption of the MICA Courses}

When creating the MICA program in 1999-2000, the departmental TFC proposed a Teaching Philosophy that included the statement, "To encourage creativity, the three MICA courses will challenge students with difficult projects that require them to 
develop their own strategies for handling complex real-world mathematics problems." This evolved into a more concrete statement as found in the current MICA program description:

students [in MICA I-II courses] will confront problems from pure and applied mathematics that require experimental and heuristic approaches. In dealing with such problems, students will be expected to develop their own strategies and make their own choices about the best combination of mathematics and computing required in finding solutions. (Brock calendar 2014)

From this, individual MICA course proposals were detailed in the program plan that, in turn, led to short course description summaries in a format required by the institution, and that are currently still in use for MICA I and MICA II courses. We provide details for each course.

The MICA I half-year course was initially proposed as "the first in a sequence of three courses that emphasize the creative application of mathematics to solving problems using computers". Its proposed course objectives are:

the primary goal of the MICA course sequence is to help students apply mathematical concepts by using computers to creatively explore solutions to mathematical problems. The second goal is to help students build a portfolio of techniques which they are confident in applying to a diverse range of mathematical problems that may or may not have exact solution.

This description is not specific to the MICA I course, but rather provides information about the overall viewpoint of the MICA courses. However, a detailed list of mathematical topics, together with specific planned computer programs, and a list of minimum skills, were presented. The mathematical topics are found, in part, in the official course description in Brock calendar (2014), unchanged since 2001: "Exploration of ideas and problems in algebra, differential equations and dynamical systems using computers. Topics include number theory, integers $\bmod p$, roots of equations, fractals, predator-prey models and the discrete logistic equation for population growth". For many years, the course syllabus distributed to students has declared the following course philosophy:

This course will encourage you to be creative in using computers to explore mathematical problems and communicate mathematical ideas. The lectures will offer you interesting mathematical problems and points of view and it will be largely up to you to choose how to explore these problems and communicate what you find.

The full year MICA II course was proposed by the TFC as "Applications of mathematics including simulation and modelling. This course is the second of the three MICA courses that focus on the connections between mathematics and technology." The course objectives provide insights into the course: "Mathematical models of all types; theory and application. Students will be expected to do at least two major projects that demonstrate creative application of the course content. One of the projects 
must use current data from research at the university", with a suggested textbook on mathematical modelling (Mooney and Swift 1999). Similar to the MICA I course, the TFC presented a detailed description that has been summarized in the institutional format:

Theory and application of mathematical models; discrete dynamical systems; time series and their application to the prediction of weather and sunspots; Markov chains; empirical models using interpolation and regression; continuous stochastic models; simulation of normal, exponential and chi-square random variables; queuing models and simulations, use of a computer algebra system. (Brock calendar 2014)

The objectives listed in one of the two MICA II teaching faculty's 2013-14 course syllabus provides additional insight into the nature of the course: "The main objective of this course is to learn basic methods of mathematical modelling and of "experimental mathematics'. Computational and algorithmic methods and use of computers simulations will be strongly emphasized. Topics include: working with data, discrete deterministic dynamics, ...". The other faculty's 2013-14 course syllabus lists examples of microworld-type projects that each student is to create during the course; for example, "Simulate battles between armies. (Stochastic Processes and Differential Equations)" and "Zoom in on bifurcations in chaotic systems. (Discrete Dynamical Systems)".

As for the full-year MICA III course, it was proposed by the TFC as "Advanced applications of mathematics including modelling and simulation. This course completes the mathematics/ technology sequence begun in MICA", with similar objectives as for MICA II, but with mention of the "Study of advanced mathematical problems", and with a suggested textbook on advanced mathematical modelling (MestertonGibbons 1995). The MICA III official description summary, from 2001 to 2009, reflects the proposed course: "Advanced applications of mathematics involving computers. Topics may include deterministic models; equilibrium; optimal control; probabilistic models; [...]". This original course content was, however, never taught (cf. issues of 'fidelity' - see Fullan and Pomfret 1977). The content was instead modified by the two faculty who taught the course to be in line with their own mathematical interests. Some students questioned the core relevance of this course to their program of study. In 2008-09, the departmental curriculum committee raised the issue of having this course, as presently taught, classified as a 'MICA' course, since it was very content-driven (i.e., about partial differential equations), and debated whether this course should remain a core course. The Department decided to keep the course content as it was presently taught, but to split the full-year core course into two one-semester elective courses. In other words, the course, as presently taught, was not perceived as a 'MICA' course. The description of these two elective courses, now called Applied Mathematics with Maple and Partial Differential Equations in $\mathrm{C}++$, can be found in the Brock calendar (2014).

\section{Implementation: the Mathematical Microworld Tasks in MICA Courses}

As mentioned in the introduction, in the three-term MICA course sequence students learn to design, program and use interactive digital environments in order to investigate 
a mathematics conjecture, theorem, concept or real-world situation, which we called 'exploratory objects' (Muller et al. 2009). Mavrikis et al.'s (2008) view of microworlds maps closely onto our perception of exploratory objects in the Brock MICA courses: MICA students construct (i.e., design and code) digital environments to explore mathematics concepts and their relationships represented in diverse forms (in the code and in the interface). This activity of creating and using mathematical microworlds is central to the MICA courses (Buteau et al. 2014b) and is well reflected in each MICA course's evaluation scheme that assigns some $78 \%$ of the total grade to microworld projects. In the following, we focus on a description of the course implementation around student microworld activity.

The MICA course format for each term is two hours of lecture and two hours of computer laboratory sessions weekly. In the first-year MICA course, students learn to program (in VB.NET) and to create and use the mathematics microworlds (i.e., exploratory objects). Whereas lectures provide the mathematical content, the laboratory sessions, complemented by four individual microworld projects, have been carefully designed to support students' learning of programming for their creation and use of mathematics microworlds (Buteau and Muller 2014). In the full second-year MICA course, students create and use mathematics microworlds in relation to a broad range of topics through ten individual microworld projects. VB.NET is a programming language similar to $\mathrm{C}++$. It is used in MICA courses through Visual Studio, a development environment which in particular enables easy design of graphical interfaces through its drag-and-drop functionality. Since VB.NET contains basic mathematics functions but no mathematical symbolic or graphical package as found in a CAS, the programming of mathematics (including graphical and visual representations) is therefore at the core of the MICA student microworld activity.

Among the 14 individual microworlds that MICA students construct over the three terms, 11 projects are assigned through guidelines provided to students. For example, each first-year MICA student usually creates a microworld to explore the dynamical system based on a cubic equation involving two parameters and then uses it to describe its behaviour (Fig. 1a). Also, each second-year MICA student usually creates a microworld that involves the process of cellular automata to simulate epidemics, in order to examine the effects of inoculation on the spread of epidemics, as well as the associated cost (Fig. 1b). In short, the mathematics content covered in the MICA I course has remained more or less unchanged since 2001, whereas the content in MICA II courses has evolved both over the years and according to the instructor's

a

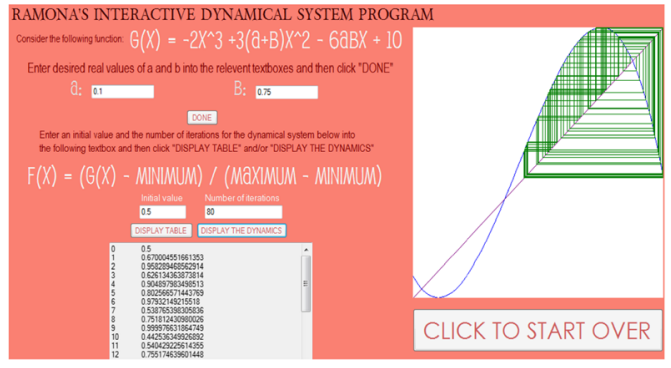

b Ramona's "Epidemic Basic"

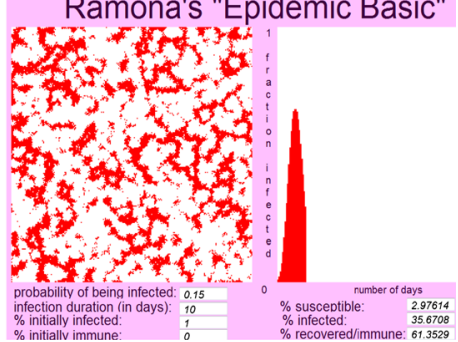

Fig. 1 Screen shots of two assigned microworlds by student Ramona (Buteau et al. 2014b) 
mathematics interests. It includes topics that lead students to "do things with a computer that would be impossible without it" (Healy and Kynigos 2010, p. 65); for example, discrete and continuous dynamical systems, RSA encryption; Markov chains, Buffon's needle problem and Monte Carlo integration, the Lotka-Volterra predatorprey model, Lanchester's equation for simulation of battles, modelling of traffic light synchronization, statistical applications to the stock market - see Buteau et al. (2014b) for an example of the complete mathematics curriculum covered in MICA courses by the 2011-12 cohort.

The other three microworld projects are on a topic individually selected by the students themselves: they are completely open projects and these may be done in pairs. For example, MICA students Matthew and Kylie wondered if it were better to walk or run in the rain (Fig. 2a), while Adam investigated the bounded area, as the exponent increases, of the iterative complex function defining the Mandelbrot set (Fig. 2b). The creation and use of microworlds is done only in part during laboratory sessions, and mostly outside classroom time as assignments.

In short, for each of his/her microworld projects, a student starts from scratch (no interface; no code), builds an exploratory learning environment (interface and code for functionalities) and uses it to conduct a certain mathematical investigation that $\mathrm{s} / \mathrm{he}$ summarizes in a written report (including any findings). Based on insightful observations, a preliminary task analysis led us to detail the MICA student's process of creating and using a mathematics microworld as a sequence of steps and cycle (Buteau and Muller 2010); see Fig. 3. In Buteau and Muller (2014), we exemplify the process based on a thorough examination of Adam's microworld (Fig. 2b) and his written report, as well as an informal interview with Adam:

Adam Profetto, enrolled in MICA II course, was interested in investigating the Mandelbrot set. His initial aim was to visualise the set and its self-similarities, together with its related Julia Set. Since the Mandelbrot Set is defined by use of a recursive quadratic polynomial, Adam set his investigation to consider also higher degree polynomials (Step 1). As mentioned in the Special Thanks and Credit section of his Exploratory Object, Adam researched his topic by use of a textbook (Step 2). He developed his Exploratory Object to visualise sets

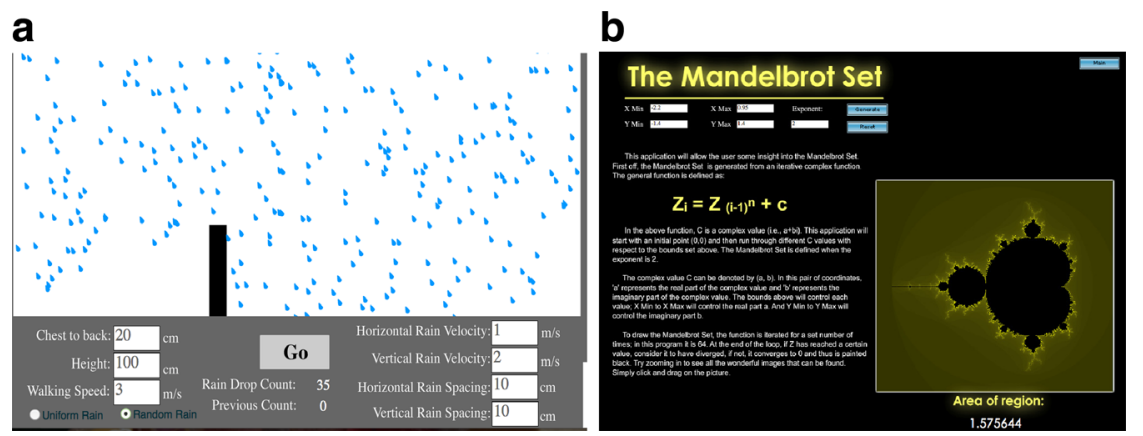

Fig. 2 To the left, Matthew and Kylie's real-world situation microworld: "Is it better to walk or run in the rain?"; to the right, Adam's pure mathematics microworld about the bounded area of the iterative complex function defining the Mandelbrot set as the exponent increases. a Matthew and Kylie's real-world situation microworld; b Adam's pure mathematics microworld 


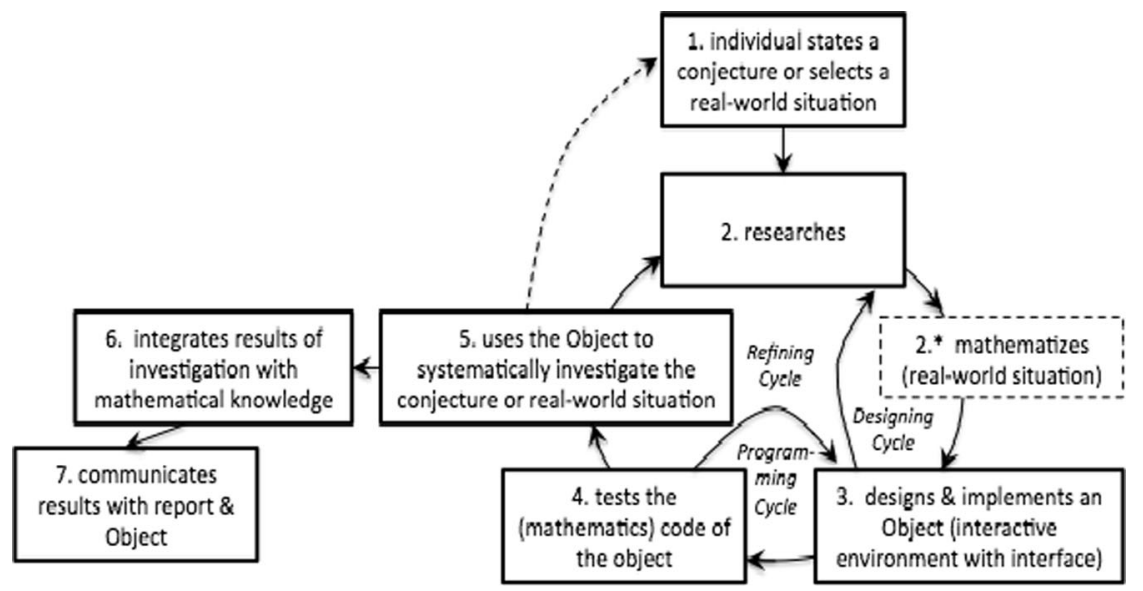

Fig. 3 MICA student's development process model of a microworld for an investigation of a mathematical concept, conjecture, or application (Buteau and Muller 2010; Marshall and Buteau 2014)

(overview) and to graphically explore the similarities through a manual zoom-in access: with the mouse or with manually entered complex plane coordinates. The related Julia Sets are displayed through a mouse-click on a point in the Mandelbrot set (Steps 3-4). Adam writes, "[This Exploratory Object project] opened up a world of interest for me and pushed my programming and patience to the max." Adam mentioned in an informal discussion that whilst exploring graphically the Mandelbrot Set with a systematic increase of the integer exponent parameter (Step 5), he became intrigued as to how it affected the area of the bounded regions defined by the sets. He thereafter extended his Exploratory Object (Refining cycle) to systematically calculate the area of the bounded regions, as the exponent increases, by repeating a Monte Carlo Integration approximation method. Adam chose to have the results represented in a two-dimensional graph in Observations and Findings section of his Exploratory Object. Adam proudly describes his findings in this section:

Firstly, the area of the Mandelbrot Set was found to be Pi/2!! This is amazing.... This is where the magic starts to happen. As the exponent $\mathrm{n}$ is increased the areas of the generated regions will also start to increase. However, shortly after, they start to converge back to a fixed value. Can you guess what that fixed value is? Yes, that's right. $\mathrm{Pi} / 2$ !!

His excitement was utmost after he searched on the Web about this result but said he could not find evidence of it as a known result. Adam (Profetto) therefore summarised this result as 'Profetto's Conjecture' not only in his written report, but also in his Exploratory Object (Step [7]). (pp. 171-2)

We argue that this model (Fig. 3) indirectly provides some insight into a student's potential engagement in the mathematical task when creating and using his/her microworld as part of the MICA courses. See Buteau et al. (submitted) for a detailed 
discussion of a MICA student's mathematics learning experience throughout her 14 microworld projects over a period of 16 months.

\section{The Student Outcome: Students' Views on their Learning Experience in MICA Courses}

The MICA I-II student and teaching assistant participants $(n=60)$ indirectly gave us their views on their learning experience in the MICA courses through a survey (Buteau et al. 2014b, d). The main idea that dominates their responses to the open question about how they would describe the MICA courses is to learn (to do) mathematics with programming/technology/computing, which, as such, stresses the non-content-driven characteristic of the MICA courses. This is illustrated in the following selected six participants' responses:

[Student A] It is a math course that provides you the tools necessary to begin exploring mathematical concepts using technology. It is incredibly interesting and very hands-on.

[Student B] The courses teach you how to use an interactive programming environment $[. .$.$] and allows you to use it to investigate different mathematical$ theorems and concepts. It is very effective because it allows you to make your own program to be able to see how this concept works, and play around with it to reach a further understanding of the concept.

[Student C] You create programs that use [mathematical] concepts and bring them to life to create a more concrete understanding of math and what it accomplishes.

[Student D] It involves learning programming language to run mathematical simulations. In addition, it is also very beneficial to future teachers as it provides a unique opportunity to visually express math concepts and engage student learning.

[Student E] You take real life math problems and write a program on the computer to react [to] the said problem. You use your program to graph and simulate the problems.

[Student F] Overall, these courses are meant to provide students with both the tools and the mindset to tackle a wide variety of mathematical problems efficiently, through the use of modern computer softwares.

Many participants also alluded to the fact that their programming and use of mathematics microworlds enhanced or made more concrete their understanding of mathematics concepts (e.g., Students B and C). For example, Student B suggests engaging in articulating relationships involved in the investigated concepts, which Noss and Hoyles (1996, p. 54) associate with the process of mathematics learning. Students also acknowledge engaging in exploring, investigating and simulating 
mathematics concepts and real-world situations (e.g., Students A, B, D, E, and F), which we interpret as an indication that the students view having developed the skills and procedures to engage in this kind of mathematical work.

\section{The Implicit Constructionist Nature of MICA Courses}

As mentioned in the Introduction, the MICA courses did not evolve out of the constructionist movement (Harel and Papert 1991). Nevertheless, we argue that the MICA courses can be categorized as constructionist.

In MICA courses, students construct (or make) at least 14 microworlds (i.e., digital objects that are shareable) during their undergraduate studies, with the aim of investigating a mathematical concept, theorem, conjecture or application. As part of their microworld projects, students sum up their mathematical investigations in a written report. This could be interpreted as aiming at prompting students to engage consciously in their construction (or at least to be reflective post-construction and use). These microworld projects being the central tasks of the MICA courses indicates that it is 'intended' that students learn mathematics by making. In particular, the model shown in Fig. 3 suggests that a MICA student might engage in constructing, changing, extending and exploring the rules and relationships of a microworld itself through succinct feedback. This is what Healy and Kynigos (2010, p. 64) refer to as "a kind of learning, which characterises the constructionist perspective of Papert et al. (Papert 1991; Kafai and Resnick 1996)".

MICA courses involve open computer-based projects, as constructionist situations often do (Papert 1991). In particular, the implementation of the three original microworld projects for which students independently determine their topics provide opportunities for students to engage in an exploration meaningful to them (see Fig. 2). Furthermore, the departmental TFC document suggests that the department seriously considered the idea of engaging in projects meaningful to others. For example, in the description of MICA II, it states: "One of the [two major] projects must use current data from research at the university", pointing to projects meaningful to the home university community. We also suggest that the overall mathematics content of MICA I-II courses, which has been carefully selected to be amenable to learning mathematics by creating and using microworlds, supports this constructionist principle. In short, this suggests that the department has implemented a learning environment through the MICA courses that provides an opportunity for, and encourages students to engage in, the constructionist learning of mathematics.

Students have described their experience in MICA courses not only in terms of the making of mathematics microworlds, but also suggesting a perceived 'tangible' mathematics; e.g., "[it is] very hands-on" and "[you] create programs that use [mathematical] concepts and bring them to life". Furthermore, all the student comments cited in the previous section express a sense of empowerment. For example, Student B appears to have reached a certain fluency in creating microworlds and thereby feels confident enough to learn mathematics on his/her own with the help with his/her self-generated microworld. The student also indicates appreciation of this intellectual independence by using the expression "it is very effective". We add that results of our preliminary empirical study (Buteau et al. 2014d) about competencies developed through the MICA 
courses suggest that students perceive developing, to some greater or lesser extent, fifteen of them. These include the following: i) self-motivation to learn/do mathematics; ii) engagement in the process of mathematics research; iii) learning/doing mathematics independently.

We suggest that this trio provides further indication that the students perceive being empowered through their MICA course experience. However, for some students, their engagement in MICA courses does not seem to provide an empowering constructionist experience, as was underscored by a small number of our survey participants. For example, a student indicated: "I was not able to self-motivate myself. Sometimes I was not even able to understand these mathematical models because I was too focused on getting the code right. It was a very stressful course." For this student, and for a few others, the evolving programming requirements throughout the courses were such that they prevented them from engaging fully with the mathematics.

Looking at the early course development, we suggest that, in fact, these courses intended to meet what can be described as constructionist principles. First, we postulate that Ralph might have observed his tutored individual gifted school students experiencing constructionist learning of mathematics. Indeed, Ralph's experience could be related to what Papert (1980a) had observed with kids working with LOGO Turtle: "I have seen children engaged in animated conversations about their own personal knowledge as they try to capture it in a program to make a Turtle carry out an action that they themselves know very well how to do" (p. 28). Papert further commented: "the child is learning technical knowledge as a means to get to a creative and personally defined end. There will be a product. And the teacher as well as the child can be genuinely excited by it" (p. 134). Second, Ralph mentioned that he aimed at recreating the individual experience of his gifted students in the MICA mathematics class. Not only does 'learning mathematics by making' seem to have been an explicit intention by Ralph when designing the MICA courses, but also the engagement in meaningful projects, for example wishing that each student in the class could express: 'I did something related to me'. In addition, he indicated that he envisioned a 'non-traditional' classroom to implement the paradigm he had in mind. This need for a different teaching paradigm when integrating mathematics microworlds into the classroom was mentioned, for example by Papert: "the relationship of the teacher to learner is very different: the teacher introduces the learner to the microworld in which discoveries will be made, rather than to the discovery itself" (1980b, p. 209).

\section{The 'Form' of Constructionist Innovation Adopted by the Stakeholders}

When the MICA courses were created and adopted, Ralph not only provided a vision, but also the necessary leadership to implement it. At that time, the mathematics department was: i) experiencing a substantial decrease in student enrolments; ii) collegial in its approaches and interactions; iii) led by an empowering Chair. Also, many of the faculty were seeing the benefits of using appropriate technology in learning of mathematics. In this section, we examine the dominant elements defining MICA courses used by the department (i.e., the stakeholders) to describe the intended, implicitly constructionist, implementation formally. 
The adopted description of MICA courses involved: i) pragmatic pedagogical aspects; ii) intended learning outcomes; iii) aspects of the philosophy concerned with the courses. Three dominant elements seem to prevail throughout the formal documents, all of which are explicitly or implicitly connected to constructionism. First and foremost, the MICA courses contain individual student mathematics projects involving and requiring engagement with programming technology, thus is implicitly related to 'learning by making'. For example, the departmental TFC explicitly mentions open projects (e.g., for the MICA II course): "Students will be expected to do at least two major projects that demonstrate creative application of the course content". A detailed list of specific planned computer programs, aligned with mathematical topics, was also provided, highlighting explicitly planned student microworld projects.

A second dominant element that occurs is in the context of student outcomes: the idea of empowering students described in pragmatic ways. For example, in the teaching philosophy, one reads: "students will be expected to develop their own strategies and make their own choices [... for] finding solutions". It also indicates, with a more direct approach, that the goal "is to help students build a portfolio of techniques which they are confident in applying to a diverse range of mathematical problems". In the MICA I course syllabus, the idea of empowering and engaging students in mathematics learning/doing is stressed again, also pointing to a different pedagogy: "This course will encourage you to be creative [...] and it will be largely up to you to choose how to explore".

A third dominant idea in the MICA course descriptions is creativity, a concept connected to constructionism. The departmental TFC document stresses numerous times the importance of creativity in many different forms. For example, in the departmental teaching philosophy: "To encourage creativity", and in the MICA I description: "apply mathematical concepts by using computers to creatively explore solutions to mathematical problems". This emphasis on creativity could be interpreted to suggest an implicit aim by the department to have students learn in a constructivist way, a connection between the creative process and constructivist theories of learning mentioned by Girvan (2014). And this aim is specifically to be achieved as students (learn to) design, program and use mathematics microworlds. In this context, this seems to indicate that the department implicitly viewed students, in MICA courses, learning through an approach different from a usual instructional approach. Also, although not as strongly present, part of the course description included the explicit indication of prompting students to engage in meaningful projects in the context of the university research community: "One of the [two MICA II major] projects must use current data from research at the university".

In short, we have summarized the dominant elements in the formal description of MICA courses, all of which can be connected to constructionism, to provide a clear sense of both the 'what' (students learn (to do) mathematics by programming and using microworlds) and the 'why' (aiming at empowering students), as well as an indication of 'how' (implicitly aiming at student learning by explicitly valuing and encouraging creativity and engaging in projects meaningful to the community). However, Ralph (2014) underlines that MICA is only one of many possible examples of university courses that can provide opportunities for students to develop what he called their linked knowledge. He proposes that: 
Linked knowledge would revolve around Technology Assisted Problem Solving and Information Retrieval or TAPSIR for short. TAPSIR pedagogy is in its infancy and is so different from traditional teaching that most of us, including myself, are nervous about handling its implementation. (p. 22)

He concludes with a number of recommendations, including:

1. Develop pilot projects for the exploration of TAPSIR pedagogy in mathematics.

2. At each grade level and in university, develop a mathematics curriculum for Linked Knowledge which would consist of skills and information that require the use of computers, smart phones, the internet, etc.

3. In several different contexts, students should learn to write sequences of instructions for computer programs to execute. (p. 23)

\section{Concluding Remarks}

The Brock department of mathematics and statistics created, adopted, and since 2001 implemented a sequence of novel technology-rich mathematics core courses for all its majors and future mathematics teachers. As part of the revised program, these MICA courses defined the core syllabus, together with algebra, calculus, differential equations, probability and statistics. Although the use of digital technology in the latter traditional courses was encouraged, when appropriate, their curricula were not significantly changed. On the other hand, in the MICA courses, the mathematics curriculum is driven by the technology as we have described in this article. In order to be adopted by the department, this required many discussions among colleagues about the role of (programming) technology in mathematics education, and how it would affect a mathematics curriculum and pedagogy (Buteau and Muller 2014).

In this article, we examined the formal MICA course description adopted by the department. The process of adoption of such innovative core courses by a whole department, and their sustained implementation, involved much more than mere course descriptions and the leadership over the long run of their main designer(s). For example, Jarvis et al. (2014) point to the fact that sustained implementation integrating technology at the university departmental level, including its adoption, is grounded in a combination of many factors, including "a dedicated core group led by a committed advocate in a position of influence/power; a strong and shared incentive for change; [...] an administration which supports creative pedagogical reform and well-considered risk-taking" (p. 117).

This process of design and adoption of the MICA courses took place outside a mathematics education research context or purpose. In particular, this meant that these courses were not explicitly intended to be of constructionist nature. However, by using Fullan and Pomfret's (1977) model of the complete process of innovation implementation, one that separates the design and adoption stage from the implementation and student outcome stages wherein constructionism principles could subsequently be identified, we were able to establish that the MICA courses provide a learning environment that aims to prompt students to engage in a constructionist learning of mathematics. This is in line with the Kynigos (2012) statement that: 
Constructionism takes on board the notion that meanings are in any way generated to some extent outside the control of a teacher or the sequencing of an activity. In designing educational activities therefore didactical intervention can at most aim to help. (pp. 16-17)

We have not directly examined whether or not students actually do experience constructionist learning of mathematics, although our survey data suggests that it is the case for at least some students. In fact, a recent study, examining the students' engagement in the design and use of mathematics microworlds throughout their 14 projects over 16 months (Buteau et al. submitted), provides further insight into how the students' mathematical knowledge grew alongside their microworld tools (cf. Hoyles 1993). The foci of our studies have thus far been on individual experiences and have not included interaction between peers. As such, we have not yet examined how students negotiate mathematical ideas among themselves as they share their in-progress or completed microworld artefacts - an important aspect of constructionism.

Kynigos (2012) asserts that, "A mathematics designed with a constructionist agenda in mind can only become part of school mathematics if the associated practices are given legitimacy by the various stakeholders involved" (p. 12). The examination of the Brock University case brought forth three main elements that led to legitimize, for members of a university mathematics department, a constructionist course implementation in the adoption stage. These are:

i) students learn (to do) mathematics by programming and conducting their own mathematical explorations;

ii) an explicit aim of empowering students articulated in pragmatic ways (e.g., support "students [to] build a portfolio of techniques which they are confident in applying to a diverse range of mathematical problems");

iii) an implicit acknowledgement of intended student constructionist learning, e.g., through the explicit role of the instructor to foster and value students' creativity in mathematical work.

These, we argue, provide an alternative means to portray constructionism in university mathematics education concretely, bringing together student experiences and pedagogy. The legitimacy of the practices adopted and implemented in the MICA courses since 2001 is now strengthened by the position of a broader community of stakeholders. Indeed, the Society for Industrial and Applied Mathematics (SIAM 2012) indicates that programming and computer skills are the most important technical skills that new mathematician hires take to their jobs. Furthermore, the European Mathematical Society (EMS 2011) states that, "Together with theory and experimentation, a third pillar of scientific inquiry of complex systems has emerged in the form of a combination of modeling, simulation, optimization and visualization" (p. 2).

Acknowledgments Our sincere thanks to Bill Ralph for sharing his experience with us. Also, we would like to thank the reviewers for all their comments. 


\section{References}

Abrahamson, D., Berland, M., Shapiro, B., Unterman, J., \& Wilensky, U. (2006). Leveraging epistemological diversity through computer-based argumentation in the domain of probability. For the Learning of Mathematics, 26(3), 39-45.

Brock calendar. (2014). http://www.brocku.ca/webcal/.

Buteau, C., \& Muller, E. (2010). Student development process of designing and implementing exploratory and learning objects (pp. 1111-1120). In V. Durand-Guerrier, S. Soury-Lavergne, \& F. Arzarello (Eds.), Proceedings of CERME 6. Lyon: Institut National de Recherche Pédagogique.

Buteau, C., \& Muller, E. (2014). Teaching roles in a technology intensive core undergraduate mathematics course. In A. Clark-Wilson, O. Robutti, \& N. Sinclair (Eds.), The mathematics teacher in the digital era: An international perspective on technology focused professional development (pp. 163-185). Dordrecht: Springer.

Buteau, C., Jarvis, D., \& Lavicza, Z. (2014a). On the integration of computer algebra systems (CAS) by Canadian mathematicians: Results of a national survey. Canadian Journal of Science, Mathematics, and Technology Education, 14(1), 35-57.

Buteau, C., Marshall, N., \& Muller, E. (2014b). Learning university mathematics by creating and using fourteen 'microworlds'. In G. Futschek \& C. Kynigos (Eds.), Proceedings of the 3rd International Constructionism Conference (pp. 401-406). Vienna: Österreichische Computer Gesellschaft.

Buteau, C., Marshall, N., \& Muller, E. (2014c). Perception on the nature of core university mathematics microworld-based courses. In G. Futschek \& C. Kynigos (Eds.), Proceedings of the 3rd International Constructionism Conference (pp. 379-389). Vienna: Österreichische Computer Gesellschaft.

Buteau, C., Muller, E., \& Marshall, N. (2014d). Competencies developed by university students in microworld-type core mathematics courses. In C. Nicol, P. Liljedahl, S. Oesterle, \& D. Allan (Eds.), Proceedings of PME 38/PME-NA 36 Conference (Vol. 2, pp. 209-216). Vancouver: PME.

Buteau, C., Muller, E., Marshall, N., Sacristán, A., Mgombelo, J. (forthcoming). Undergraduate mathematics students appropriating programming as a tool for modelling, simulation and visualization: A case study. Accepted pending revisions for publication in DEME.

EMS (2011). Position Paper of the European Mathematical Society on the European Commission's Contributions to European Research [online]. Available: http:/www.euro-math-soc.eu/files/ EMSPosPaper13_03_2011_NP.pdf.

Fullan, M., \& Pomfret, A. (1977). Research on curriculum and instruction implementation. Review of Educational Research, 47(2), 335-397.

Girvan, C. (2014). Constructionism, creativity and virtual worlds. In G. Futschek \& C. Kynigos (Eds.), Proceedings of the 3rd International Constructionism Conference (pp. 367-377). Vienna: Österreichische Computer Gesellschaft.

Guilford, J.P. (1950). Creativity. American Psychologist 5, 444- 454.

Harel, I., \& Papert, S. (1991). Constructionism. Norwood: Ablex Publishing Corporation.

Healy, L., \& Hoyles, C. (1999). Visual and symbolic reasoning in mathematics: making connections with computers? Mathematical Thinking and Learning, 1(1), 59-84.

Healy, L., \& Kynigos, C. (2010). Charting the microworld territory over time: design and construction in mathematics education. ZDM the International Journal of Mathematics Education, 42(1), 63-76. doi:10. 1007/s11858-009-0193-5.

Hillel, J. (2002). Trends in curriculum. In D. Holton (Ed.), The teaching and learning of mathematics at university level: An ICMI study (pp. 59-69). Dordrecht: Kluwer Academic Publishers.

Hoyles, C. (1993). Microworlds/schoolworlds: The transformation of an innovation. In C. Keitel \& K. Ruthven (Eds.), Learning from computers: Mathematics education and technology (pp. 1-17). Heidelburg: Springer.

Hoyles, C. (2014). Contribution to the panel discussion 'Whatever happened to the powerful ideas?'. The 3rd International Constructionism Conference. Vienna, AT: Österreichische Computer Gesellschaft.

Hoyles, C., \& Noss, R. (1987). Seeing what matters: developing an understanding of the concept of parallelogram through a Logo microworld. In J. Bergeron, N. Herscovics, \& C. Kieran (Eds.), Proceedings of the 11th Conference of the International Group for the Psychology of Mathematics Education (Vol. 2, pp. 17-24). Montréal: PME.

Hoyles, C. \& Noss, R. (2014). Why should we teach children to program, really? Invited keynote presentation at the Third International Constructionism Conference [video file]. Vienna, AT: Österreichische Computer Gesellschaft. Retrieved from: https://www.youtube.com/watch?v=AVwtcI4bBCU\&list= UUldl-JvVdukFpWdImz3NDCA. 
Jarvis, D., Lavicza, Z., \& Buteau, C. (2014). Systemic shifts in instructional technology: findings of a comparative case study of two university mathematics departments. The International Journal for Technology in Mathematics Education, 21(4), 117-142.

Kafai, Y., \& Resnick, M. (Eds.). (1996). Constructionism in practice: Designing, thinking, and learning in a digital world. Mahwah: Lawrence Erlbaum Associates.

Kynigos, C. (2007). Using half-baked microworlds to challenge teacher educators' knowing. International Journal of Computers for Mathematical Learning, 12(2), 87-111. doi:10.1007/s10758-007-9114-2.

Kynigos, C. (2012). Constructionism: Theory of learning or theory of design? Paper presented at the $12^{\text {th }}$ International Congress on Mathematical Education: Seoul, KR.

Kynigos, C. (2015). Constructionism: Theory of learning or theory of design? In J. Sung (Ed.), The Proceedings of the 12th International Congress on Mathematical Education: Intellectual and Attitudinal Challenges (p. 361). Cham: Springer.

Leron, U., \& Dubinsky, E. (1995). An abstract algebra story. The American Mathematical Monthly, 102(3), $227-242$.

Marshall, N., \& Buteau, C. (2014). Learning by designing and experimenting with interactive, dynamic mathematics exploratory objects. The International Journal for Technology in Mathematics Education, 21(2), 49-64.

Marshall, N., Buteau, C., \& Muller, E. (2014). Exploratory objects and microworlds in university mathematics. Teaching Mathematics and its Applications, 33(1), 27-38.

Mascaró, M., Sacristán, A., \& Rufino, M. (2014). Teaching and learning statistics and experimental analysis for environmental science students, through programming activities in R. In G. Futschek \& C. Kynigos (Eds.), Proceedings of the 3rd International Constructionism Conference (pp. 407-416). Vienna: Österreichische Computer Gesellschaft.

Mavrikis, M., Geraniou, E., Noss, R., Hoyles, C. (2008). Revisiting pedagogic strategies for supporting students' learning in mathematical microworlds. In S., Gutierrez-Santos and M. Mavrikis, Proceedings of the International Workshop on Intelligent Support for Exploratory Environments at EC-TEL (pp. 41-50). Maastricht, NL: CEUR-WS.org, online CEUR-WS.org/Vol-381.

Mesterton-Gibbons, M. (1995). A concrete approach to mathematical modelling (2nd ed.). New York: Wiley.

MICA (n.d.). Exploratory and learning objects created by Brock students in mathematics courses [Online]. Available: www.brocku.ca/mathematics/studentprojects.

Misfeldt, M. \& Ejsing-Duun, S. (2015). Learning mathematics through programming: An instrumental approach to potentials and pitfalls. Paper presented at CERME 9. Prague, CZ.

Mooney, D., \& Swift, R. (1999). A course in mathematical modeling. Washington, DC: Mathematical Association of America.

Muller, E., Buteau, C., Ralph, W., \& Mgombelo, J. (2009). Learning mathematics through the design and implementation of exploratory and learning objects. The International Journal for Technology in Mathematics Education, 16(2), 63-74.

Noss, R., \& Hoyles, C. (1996). Windows on mathematical meanings: Learning cultures and computers. Dordrecht: Kluwer Academic Publishers.

Papert, S. (1980a). Mindstorms: Children, computers, and powerful ideas. New York: Basic Books.

Papert, S. (1980b). Computer-based microworlds as incubators for powerful ideas. In R. Taylor (Ed.), The computer in the school: Tutor, tool, tutee (pp. 203-210). New York: Teacher's College Press.

Papert, S. (1990). A critique of technocentrism in thinking about the school of the future. Epistemology and Learning Group Memo No. 2 (September 1990), MIT Media Laboratory. Retrieved from: http://www. papert.org/articles/ACritiqueofTechnocentrism.html.

Papert, S. (1991). Situating constructionism. In I. Harel \& S. Papert (Eds.), Constructionism (pp. 1-11). Norwood: Ablex Publishing Corporation.

Papert, S. (1996). An exploration in the space of mathematics educations. International Journal of Computers for Mathematical Learning, 1(1), 95-123.

Pesonen, M., \& Malvela, T. (2000). A reform in undergraduate mathematics curriculum: more emphasis on social and pedagogical skills. The International Journal of Mathematical Education in Science and Technology, 31(1), 113-124.

Ralph, W. (1999). Journey through calculus. Pacific Grove: Brooks/Cole/Thomson Learning (CD-ROM).

Ralph, W. (2001). Mathematics takes an exciting new direction with MICA program. Brock Teaching, 1(1), 1. Available: http://www.brocku.ca/webfm_send/18483.

Ralph, W. (2014). Are we teaching Roman numerals in a digital age? In S. Oesterle \& D. Allan (Eds.), Proceeding of the Canadian Mathematics Education Study Group 37th Annual Meeting (pp. 19-24). St Catharines: CMESG/GCEDM. 
SIAM (2012). Mathematics in industry report. Retrieved from: http://www.siam.org/reports/mii/2012/report. pdf.

Steen, L. (1992). 20 questions that deans should ask their mathematics department. Bulletin of the American Association of Higher Education, 44(9), 3-6.

Sutherland, R. (1987). A study of the use and understanding of algebra-related concepts within a Logo environment. In J. Bergeron, N. Herscovics, \& C. Kieran (Eds.), Proceedings of the 11th PME International Conference (Vol. 1, pp. 241-247). Montréal: PME.

Wilensky, U. (1995). Paradox, programming and learning probability. Journal of Mathematical Behavior, 14(2), 231-280.

Yin, R. (2003). Case study research: Design and methods (4th ed.). Thousand Oaks: Sage Publications, Inc.

Zvoch, K. (2012). How does fidelity of implementation matter? Using multilevel models to detect relationships between participant outcomes and the delivery and receipt of treatment. American Journal of Evaluation, 33(4), 547-565. 